\section{Alternate Methods of Transplanting Pecan Trees}

\author{
Frederic B. Ouedraogo ${ }^{1}$, B. Wade Brorsen ${ }^{2}$, Jon T. Biermacher ${ }^{3}$, \\ and Charles T. Rohla ${ }^{3,4}$
}

\begin{abstract}
AdDitional Index words. Carya illinoinensis, container trees, shoot growth, taproot pruning

SumMARY. When trees with taproots are grown in containers, the taproot typically spirals around the bottom of the container. Currently, there is no consensus on what is the best thing to do about it. Pecan (Carya illinoinensis) grafted containergrown trees were transplanted under three treatment conditions. The treatments were container trees 1) planted straight from the container with no root pruning and no disturbance, 2) planted with taproots pruned so they no longer curled around the bottom of the container and with minimal disturbance of the root ball, and 3 ) planted with taproot pruned and all potting medium removed. Trunk size and shoot growth were recorded for each tree in each year during the first 4 posttransplant years (2010-14). There was no statistically significant effect of the treatments on trunk size. Shoot growth was slowed during the first year for trees with taproot pruned and potting medium removed, but there was no significant effect over the entire 4-year period.
\end{abstract}

$\mathrm{T}$ The effects on posttransplant growth of seedlings from nursery containers are well studied (Amoroso et al., 2010; Arnold and McDonald, 2006; Gilman et al., 2016; Struve, 1993). Containergrown plants may develop deformed roots during the nursery stage (Gilman et al., 2003; Lindström and Rüne, 1999), leading to long-term growth issues (Balisky et al., 1995; Lindström and Håkansson, 1995) that range from plant instability caused by uneven distribution of roots (Nichols and Alm, 1983) to reduction in shoot growth and decline of the trees (Ortega et al., 2006). In some cases, root malformation may lead to the death of the plant.

Survival and the resilience of nursery seedlings to transplant stress depends on their ability to produce a root system rapidly that is capable of invading the new soil. There are possible ways to reduce transplant stress for container-grown plants. One

The research was supported primarily by the Noble Research Institute, LLC. Support was also received from the A.J. and Susan Jacques Chair as well as the Oklahoma Agricultural Experiment Station and U.S. Department of Agriculture National Institute of Food and Agriculture Hatch Project no. OKL02939.

${ }^{1}$ American Veterinary Medical Association, Schaumburg, IL 60173

${ }^{2}$ Department of Agricultural Economics, Oklahoma State University, Stillwater, OK 74078

${ }^{3}$ Noble Research Institute, 2510 Sam Noble Parkway, Ardmore, OK 73401

${ }^{4}$ Corresponding author. E-mail: ctrohla@noble.org.

https://doi.org/10.21273/HORTTECH04180-18 treatment is to prune the taproot. When kept in the container for an extended period of time at the nursery, taproots circle around when they reach the bottom of the container. Establishment becomes a challenge for roots in such conditions (Amoroso et al., 2010). The malformation can be corrected by pruning the deformed root to allow a better root system to form. However, remediation of a deformed root by pruning may exacerbate transplant shock (Struve, 1993).

Another treatment is to remove the potting media. The $\mathrm{pH}$ level, soluble salts, and carbon-to-nitrogen ratio contained in the potting mix should meet the requirements of the plant (Ingram et al., 1993). When the potting media meet the desirable chemical properties of the plant, the root growth in the less desirable soil around the plant may be lessened. Therefore, it might be advantageous to remove the potting medium before planting so the roots acclimate to the new soil environment more rapidly. Lipe et al. (2018) recommend using a hose to wash off the outer inch of potting medium.
Pecan trees are native to the southern region of the United States and grow well in a large variety of soils. As seedling trees, pecan trees are often grafted with shoots from another donor (typically a tree with an outstanding quality of nuts). With container-grown trees, industry practice varies with regard to root pruning, root disturbance, and potting medium removal. The three planting methods for pecan trees are 1) container tree planted straight from the container with no root pruning and no disturbance (container as is), 2) container tree with a pruned taproot and minimal disturbance of the root ball (pruned), and 3) container tree with a pruned taproot and all potting medium removed (no potting medium).

No study has investigated the impacts of these planting alternatives on the growth and survival of pecan trees. There is no consensus on the best way to plant pecan trees. The nursery providing the trees recommended planting as is. Wells et al. (2015) recommend pruning the taproot with minimal disturbance. Our final treatment is meant to simulate the planting of bare-root trees, which is also a common planting method. The objective of this experiment was to determine the effects of the three alternative methods of transplanting on pecan tree growth and survival.

\section{Materials and methods}

The experiment was conducted as a completely randomized design at Rafter B Ranch, which is south of Hugo, OK (lat. $33.9371^{\circ} \mathrm{N}$, long. $\left.95.6311^{\circ} \mathrm{W}\right)$. Trees were planted in a Coushatta silty clay loam soil and were spaced $40 \mathrm{ft}$ apart as recommended by the Oklahoma Cooperative Extension Service (Carroll and Smith, 2015).

In total, 75 trees $(25$ trees per treatment group) were planted during Feb. 2010. All trees were 'Kanza' grafted on a native ('Moore' seedlings) rootstock, purchased from the same nursery, and they were the same

\begin{tabular}{llll}
\hline $\begin{array}{l}\text { Units } \\
\begin{array}{l}\text { To convert U.S. to SI, } \\
\text { multiply by }\end{array}\end{array}$ & U.S. unit & SI unit & $\begin{array}{l}\text { To convert SI to U.S., } \\
\text { multiply by }\end{array}$ \\
\hline 0.3048 & $\mathrm{ft}$ & $\mathrm{m}$ & 3.2808 \\
3.7854 & gal & $\mathrm{L}$ & 0.2642 \\
2.54 & inch(es) & $\mathrm{cm}$ & 0.3937 \\
25.4 & inch(es) & $\mathrm{mm}$ & 0.0394
\end{tabular}


Table 1. Trunk size and shoot growth of pecan trees in relation to year and planting method. Trees were planted in 2010 at Hugo, OK. The results presented are the least squares means. Random effects were included for tree and year. For shoot growth, a heteroscedasticity adjustment was used to adjust for varying number of limbs.

\begin{tabular}{|c|c|c|c|c|c|c|}
\hline \multirow[b]{2}{*}{ Planting method ${ }^{\mathrm{z}}$} & \multicolumn{5}{|c|}{ Yr } & \multirow[b]{2}{*}{ All years } \\
\hline & 2010 & 2011 & 2012 & 2013 & 2014 & \\
\hline \multicolumn{7}{|l|}{ Avg trunk diam $(\mathrm{mm})^{\mathrm{y}}$} \\
\hline Pruned & 15.7 & 18.1 & 24.7 & 37.3 & 61.6 & 31.4 \\
\hline No potting media & 15.6 & 18.0 & 24.0 & 35.1 & 57.5 & 30.1 \\
\hline \multicolumn{7}{|c|}{ Avg shoot growth $(\mathrm{cm})^{y}$} \\
\hline No potting media & - & $21.7 \mathrm{~B}$ & 31.1 & $36.6 \mathrm{ab}$ & - & 30.3 \\
\hline
\end{tabular}

${ }^{\mathrm{z}}$ Container as is = trees planted with the container removed, but everything else left intact; Pruned = taproot pruned and with minimal disturbance of the root ball; No potting media $=$ taproot pruned to 18 inches $(45.7 \mathrm{~cm})$ and the potting media removed .

${ }^{\mathrm{y}} \mathrm{l} \mathrm{mm}=0.0394$ inch, $1 \mathrm{~cm}=0.3937$ inch.

${ }^{\mathrm{x}}$ Different letters in a column indicate significant differences $(P<0.05)$ in means as determined by Fisher's least significant differences test.

age. Container trees were grown in a tree pot [height, $2 \mathrm{ft}$; width, 11 inches; volume, 8 gal (TP1124R; Stuewe and Son, Tangent, OR)] using a tree bark medium with nutrient composition developed by the nursery that provided the trees. For trees used in treatment 2 , the portion of the taproot that had curled around the bottom of the container was cut out using garden scissors. For treatment 3 , the potting medium was removed from the root system by tapping each tree on the ground before planting. This method is used for pecan trees because their root system does not have root hairs. For each tree in each treatment, the shoot growth and trunk size were measured at planting and in each year during dormancy. All trees were pruned to a $1 \mathrm{~m}$ height at planting. A caliper was used to measure the trunk 18 inches above the ground for 5 consecutive years (2010-14). Table 1 shows the average trunk size by treatment group for each year. All groups started with an average trunk size of at least $15 \mathrm{~mm}$. Current-season shoot growth was recorded for the first 3 consecutive posttransplant years (2010-12). Each limb of the tree was measured annually during dormancy before being pruned to 18 inches.

All trees in the study were managed identically following extension recommendations for a commercial orchard (Lee et al., 2013). A 12 -ft vegetation-free strip was maintained with glyphosate around the trees throughout the growing season. When rainfall was inadequate, the trees were irrigated with $l$ inch per week using a solid set irrigation system. Chlorpyrifos (Lorsban; Dow AgroSciences, Indianapolis, IN) was used to control pecan bud moth (Gretchena boliana), pecan catocala (Catocala sp.), walnut caterpillar (Datana integerrima), and grasshoppers (Caelifera sp.). Urea was applied in four split applications. Zinc sulfate was applied beginning on $20 \mathrm{Apr}$. and then every 2 weeks for a total of seven sprays per year.

To determine the effects of the different treatments on shoot growth, an average shoot growth was calculated for each tree and the group average was calculated for each treatment group. A mixed model with treatment fixed effect, year random effects, and tree random effects was used to fit the trunk size data. In addition, a tree random effect was used to control for intrinsic differences between trees.

The MIXED Procedure in SAS (SAS/STAT version 14.1 in SAS version 9.4; SAS Institute, Cary, NC) was used to estimate the parameters of the model (Little et al., 1996). To determine the effect of treatment on shoot growth, the same model was estimated with shoot growth as a response variable. Following Richter and Brorsen (2006), the NLMIXED Procedure in SAS/STAT (version 14.1, SAS Institute) was used to model the heteroscedastic variance of shoot growth across treatment groups (SAS, 2017). The heteroscedasticity was introduced by taking average growth across differing numbers of limbs. Such heteroscedasticity is common in studies with aggregate data, as seen in the work by Mitchell et al. (2018). Note that without the adjustment for heteroscedasticity we would have found statistical significance, but we include the adjustment because the tests are biased without it. The diameter measurements were taken in February or March of each year, with the last data collected in Feb. 2014. Finally, we present the number of trees from each treatment that died, but, because of the small sample, we make no conclusions regarding the effects of the treatments on tree survival.

\section{Results and discussion}

Plant growth: Trunk size. Container-grown trees showed only a modest increase during the first year, but grew well after year 1 (Table $2)$. In total, 464 observations were available. The results of type 3 test of fixed effects from the MIXED Procedure demonstrated no significant effect on trunk size from the way the seedlings were handled during transplant (we also considered growth instead of trunk size, but the conclusions regarding statistical significance were unchanged). Wood (1996) with 3-year-old pecan transplants, Zhang et al. (2015) with newly sprouted pecan seedlings, and Mucha et al. (2018) with english oak (Quercus robur) trees also found little effect of taproot pruning on tree growth.

TrEatMENT AND SHOOT GROWTH. The results showing the effect of treatments on shoot growth are presented in Table 2. The shoot growth was slowed the first year by removing the potting media. However, the differences over the entire time period were not significant.

Treatment and SURVIVAL Rate. Tree survival rates are important to 
Table 2. Number of pecan trees planted in 2010 at Hugo, OK, and number of trees that died in relation to planting method in each year after planting.

\begin{tabular}{|c|c|c|c|}
\hline Planting method ${ }^{\mathrm{z}}$ & $\begin{array}{c}\text { Time since } \\
\text { planting }(y \mathbf{r})\end{array}$ & $\begin{array}{c}\text { Trees at } \\
\text { start (no.) }\end{array}$ & Trees dead (no.) \\
\hline \multirow[t]{4}{*}{ Container as is } & $0-1$ & 25 & 0 \\
\hline & $1-2$ & 25 & 2 \\
\hline & $2-3$ & 23 & 0 \\
\hline & $3-4$ & 23 & 0 \\
\hline \multirow[t]{4}{*}{ Pruned } & $0-1$ & 25 & 2 \\
\hline & $1-2$ & 23 & 0 \\
\hline & $2-3$ & 23 & 0 \\
\hline & $3-4$ & 23 & 2 \\
\hline \multirow{4}{*}{ No potting media } & $0-1$ & 25 & 0 \\
\hline & $1-2$ & 25 & 0 \\
\hline & $2-3$ & 25 & 1 \\
\hline & $3-4$ & 24 & 1 \\
\hline
\end{tabular}

${ }^{\mathrm{z}}$ Container as is = trees planted with the container removed, but everything else left intact; Pruned $=$ taproot pruned and with minimal disturbance of the root ball; No potting media = taproot pruned to 18 inches $(45.7 \mathrm{~cm})$ and the potting media removed.

orchard owners for planning purposes. Dead trees have to be replaced, which generates extra expenses. Plant physiology determines the ability of the plant to change its metabolism to adapt to changing environments (Claeys and Inzé; 2013). A plant that has a defective root system might not be able to survive prolonged stress. Two trees with only the taproot pruned died during the first year. Each treatment also had two trees die in later years.

\section{Conclusions}

An experiment was conducted using 75 pecan trees divided equally into three treatment groups to determine the effect of treatments on tree growth. Factors under investigation were a container tree planted straight from the container with no root pruning and no disturbance, a container tree with a pruned taproot and minimal disturbance of the root ball, and a container tree with a pruned taproot and all potting medium removed.

Trees were then observed for a period of 4 years during which shoot growth and trunk size were measured annually and the number of dead trees was recorded. The results indicate that shoot growth was slowed during the first year by removing the potting medium and pruning the taproot. These trees eventually caught up enough that the difference was not significant over the entire time period. Most of the results were not statistically significant. As Gelman and Weakliem (2009) argue, if we limit publication to statistically significant effects, we will end up overestimating small effects. Although they did not meet the statistical significance criterion, both the shoot growth and trunk size measurements were greatest for the pruned taproot and no disturbance of the root ball. The most common practice is to prune the taproot and leave the potting medium in place (Wells et al., 2015), so there is nothing in this research that says those using it need to change. Our results show the trees were largely resilient to their transplanting method.

\section{Literature cited}

Amoroso, G., P. Frangi, R. Piatti, F. Ferrinin, A. Fini, and M. Faoro. 2010. Effect of container design on plant growth and root deformation of littleleaf linden and field elm. HortScience 45:18241829.

Arnold, M.A. and G.V. McDonald. 2006. Shrub rose response to production in smart pots and conventional containers using two contrasting substrates. Subtrop. Plant Sci. J. Rio Grande Valley Hort. Soc. $58: 1-4$.

Balisky, A.C., P. Salonius, C. Walli, and D. Brinkman. 1995. Seedling roots and forest floor: Misplaced and neglected aspects of British Columbia's reforestation effort. For. Chron. 71:9-65.

Carroll, B. and M.W. Smith. 2015. Establishing a pecan orchard. Oklahoma State Univ., Oklahoma Coop. Ext. Fact Sheet HLA-6247.

Claeys, H. and D. Inzé. 2013. The agony of choice: How plants balance growth and survival under water-limiting conditions. Plant Physiol. 162:1768-1779.

Gelman, A. and D. Weakliem. 2009. Of beauty, sex, and power: Too little attention has been paid to the statistical challenges of estimating small effects. Amer. Sci. 97:310-316.

Gilman, E.F., J. Grabosky, A. Stodola, and M.D. Marshall. 2003. Irrigation and container type impact red maple (Acer rubrum L.) 5 years after landscape planting. J. Arboricult. 29:231-236.

Gilman, E.F., M. Paz, and C. Harchick. 2016. Effect of container type and root pruning on growth and anchorage after planting Acer rubrum L. into landscape soil. Arboricult. Urban For. 43:73-83.

Ingram, L.D., W.R. Henley, and H.T. Yeager. 1993. Growth media for container grown ornamental plants. Univ. Florida, Florida Coop. Ext. Serv. Bul. 241.

Lee, J., P. Mulder, and G. Driever. 2013. Commercial pecan insect and disease control-2013. Oklahoma Coop. Serv. Current Rpt. CR-6209.

Lindström, A. and L. Håkansson. 1995. Going to the root of the evil. Can. Silvicult. Mag. 3:14-17.

Lindström, A. and G. Rüne. 1999. Root deformation in plantations of containergrown scots pine trees: Effects on root growth, tree stability and stem straightness. Plant Soil 217:29-37.

Lipe, J.A., L. Stein, G.R. McEachern, J. Begnaud, and S. Helmers. 2018. Home fruit production: Pecans. 3 Oct. 2018. $<$ https://aggie-horticulture.tamu.edu/ extension/homefruit/pecan/pecan. html>.

Little, R.C., G.A. Miliken, W.W. Stroup, and R.D. Wolfinger. 1996. SAS system for mixed models. SAS Inst., Cary, NC.

Mitchell, J.L., D.S. Peel, and B.W. Brorsen. 2018. Price determinants of bred cows. J. Agr. Appl. Econ. 50:64-80.

Mucha, J., A.M. Jagodziński, B. Bułaj, P. Łakomy, A.M. Talaśka, J. Oleksyn, and M. Zadworny. 2018. Functional response of Quercus robur L. to taproot pruning: A 5year case study. Ann. For. Sci. 75:22.

Nichols, C.A. and A.A. Alm. 1983. Root development of container-reared, nursery-grown and naturally regenerated pine seedlings. Can. J. For. Res. 13:239245.

Ortega, U., J. Majada, A. Mena-Petite, J. Sanchez-Zabala, N. Rodriguez-Iturrizar, K. Txarterina, J. Azpitarte, and M. Duñabeitia. 2006. Field performance of Pinus radiata $\mathrm{D}$. Don produced in nurs- 


\section{Research Reports}

ery with different types of containers. New For. 31:97-112.

Richter, F.G.-C. and B.W. Brorsen. 2006. Aggregate versus disaggregate data in measuring school quality. J. Prod. Anal. 25:279-289.

SAS. 2017. SAS/STAT 14.1 User's guide. 3 Oct. 2018. <http://support.sas. com/documentation/cdl/en/statug/
$68162 / \mathrm{HTML} / \mathrm{default} / \mathrm{viewer}$. htm\#statug_nlmixed_syntax.htm>.

Struve, D.K. 1993. Effect of coppertreated containers on transplant survival and regrowth of four tree species. J. Environ. Hort. 11:196-199.
Wells, L., W. Hudson, and J. Brock. 2015. Pecan trees for the home or backyard orchard. Univ. Georgia Coop. Ext. Bul. 1348.

Wood, B. 1996. Establishing pecan transplants. Hort Technology 6:276-279.

Zhang, R., F. Peng, P. Yan, F. Cao, and Z. Liu. 2015. Effects of root pruning on germinated pecan seedlings. HortScience 50:1549-1552. 